\title{
Chronic Pain
}

National Cancer Institute

\section{Source}

National Cancer Institute. Chronic Pain. NCI Thesaurus. Code C26940.

Ongoing or recurrent pain that persists beyond that which is expected following acute injury, usually 3 months or more. 